\begin{tabular}{|c|c|c|c|}
\hline NATA & $\begin{array}{l}8^{\text {th }} \text { CIDI } \\
8^{\text {th }} \text { Information Design } \\
\text { International Conference }\end{array}$ & $\begin{array}{l}8^{\text {th }} \text { CONGIC } \\
8^{\text {th }} \text { Information Design } \\
\text { Student Conference }\end{array}$ & $\begin{array}{l}\text { Blucher Design Proceedings } \\
\text { Junho } 2018 \text {, num. } 1 \text {, vol. } 4 \\
\text { proceedings.blucher.com.br }\end{array}$ \\
\hline
\end{tabular}

\title{
Um sistema de comunicação visual-ambiental para o complexo esportivo do Pacaembu
}

\author{
An environmental graphic design system for Pacaembu's sports complex
}

Fabio Salmoni, Sara M. Goldchmit

wayshowing, projeto, Pacaembu, informação

\begin{abstract}
A história do complexo esportivo do Pacaembu mistura-se com partes da história de São Paulo e com a história da cultura esportiva brasileira. Trata-se de um equipamento público carregado de memória simbólica, aberto ao uso da comunidade. O objetivo deste estudo é analisar as possibilidades da utilização dos elementos estáticos e dinâmicos do ambiente como interface comunicacional que aproxime os usuários do complexo esportivo do espaço que ocupam. A pesquisa foi realizada através de levantamento bibliográfico referente à sinalização, comunicação ambiental e outras nomenclaturas da área; pesquisa in loco e entrevistas com usuários; análise dos dados coletados e desenvolvimento de projeto. O resultado é uma proposta para um novo projeto de comunicação visual-ambiental para o complexo esportivo do Pacaembu. Espera-se que este estudo possa apontar soluções replicáveis em outros equipamentos públicos comunitários que ofereçam espaços de atividades físicas e lúdicas voltadas para o esporte e a qualidade de vida.
\end{abstract}

wayshowing, design, Pacaembu, information

The history of Pacaembu's sports complex mixes with parts of the history of São Paulo and with the history of Brazilian sports culture. It is a public facility loaded with symbolic memory, open to the use of the community. The aim of this study is to analyze the possibilities of using the static and dynamic elements of the environment as a communication interface that brings the sports complex' users closer to the the space they occupy. The research was carried out through a bibliographical survey related to signage, environmental communication and other nomenclatures of this study area; field research and interviews with the users; analysis of collected data and project development. The result is a proposal for a new visual-environmental communication project for Pacaembu's sports complex. It is expected that this study could point out replicable solutions for other community public facilities that offer physical and recreational activities geared toward sports and quality of life.

\section{Introdução}

O complexo esportivo do Pacaembu é um exemplo de marco arquitetônico, urbanístico e histórico, que relata o zeitgeist da cidade de São Paulo no começo do século XX. Esses pedaços remanescentes de passado, junto com a combinação desordenada de numerosos signos que competem por atenção, criam a sobrecarga de dados visuais e o ruído que podem ser tanto confuso quanto uma fonte de entretenimento para o observador atento (PAWELS, 2009). Como um sistema de símbolos, a cidade e suas imagens são produzidas, do ponto de vista de Lefebvre (1991), de acordo com uma gama de interesses onde níveis conotativos e denotativos de significação se entrelaçam e novas espécies de mitologias, mitografias e imagens urbanas emergem. Como as ocupações espaciais não são estáticas e tampouco controladas, os elementos móveis e estáticos alteram e são alterados por signos que perdem seus significados no tempo, mas continuam transmitindo suas mensagens obsoletas.

Apesar de trivial, nunca é suficiente ressaltar como a cidade de São Paulo é, dentro das grandes metrópoles mundiais, um caso único de desenvolvimento, expressão cultural e encontro de interesses dos mais diferentes públicos. Seja pela "juventude" da cidade, quando comparada a outros centros urbanos de similar importância econômica, social e cultural, ou pelo amálgama de ideologias que foram responsáveis pelo desenho do que viria a ser a cidade mais influente da América Latina (spturis.com.br, 2015). Vale lembrar que há 100 anos o bairro

Anais do 8 CIDI e 8 CONGIC

Guilherme Santa Rosa; Cristina Portugal (orgs.)

Sociedade Brasileira de Design da Informação - SBDI

Natal | Brasil | 2017

ISBN 978-85-212-1305-5
Proceedings of the $8^{\text {th }} \mathrm{CIDI}$ and $8^{\text {th }}$ CONGIC

Guilherme Santa Rosa; Cristina Portugal (orgs.)

Sociedade Brasileira de Design da Informação - SBDI

Natal| Brazil | 2017

ISBN 978-85-212-1305-5 
do Pacaembu não passava de um lote de glebas adquiridas pela City of São Paulo Freehold and Land Company (Cia. City), que havia desistido temporariamente de vender os terrenos divididos por causa da topografia de difícil ocupação.

Apesar da relevância do complexo esportivo do Pacaembu como um espaço público que agrega infindáveis simbologias do esporte e da história de São Paulo, vemos que seu rápido desenvolvimento gerou resultados pouco planejados quanto à comunicação visual-ambiental e à própria arquitetura. Trata-se, portanto, de um espaço singular para o estudo de características imagéticas, semióticas e históricas, bem como a bagagem cultural que carrega e como se constrói no imaginário de seus frequentadores.

\section{Levantamento bibliográfico: comunicação e orientação}

Observa-se que a formalização do estudo do design voltado para a comunicação ambiental é recente se comparada à sua prática - ainda que no início não houvesse qualquer planejamento e projeto para tal, portanto desqualificando a prática como design. Mais recentemente, ao final do século passado, os profissionais que projetavam para a comunicação ambiental encontravam-se majoritariamente em escritórios de arquitetura e seu trabalho de design relacionava-se a espaços arquitetônicos, de modo que o produto de seu trabalho era comumente referido como sinalização arquitetônica. Na verdade, a palavra signage, cuja origem é atribuída ao designer canadense Paul Arthur, sequer aparecia nos dicionários estadounidenses até a década de 1980. No entanto, na década de 1970, um grupo de designers encontrava-se projetando desenhos para um grupo coordenado (uma "família") de sinais e não para impressão (CALORI, 2007).

Em fontes especializadas (ADG Brasil, 2004 e MOZOTA apud VELHO, 2007) e na prática profissional encontra-se o uso de denominações diversas: sinalização, programação visual, comunicação visual, design ambiental, design total, ambientação, design da informação, wayfinding design, design gráfico-ambiental, sistemas de sinalização, sinalização interna, identificação de fachadas, etc. Neste trabalho serão utilizadas as definições de Chris Calori (2007), Joan Costa (1987), Paul Arthur e Passini (1992) e o trabalho de Ana Lúcia Velho (2007) que se apoia em diversos autores para fazer a distinção entre as áreas de estudo do design voltado para o ambiente.

O projeto de comunicação visual-ambiental faz parte de um programa de design maior que tem como objetivo otimizar a comunicação para criar um sistema de orientação próprio para a navegação no espaço. Ainda no que se refere ao ambiente, algumas considerações elaboradas do ponto de vista do marketing podem complementar a compreensão da importância do ambiente. Zeithaml e Bitner (2003 apud VELHO, 2007), consideram os ambientes como cenários de serviços (locais onde as pessoas executam tarefas), e que são percebidos pelas suas evidências físicas. Por isso é importante observar, além dos elementos planejados, as evidências do uso do espaço para entender como o ambiente influencia no fluxo e vice-versa.

O programa atual adotado pelo complexo esportivo do Pacaembu será analisado segundo as definições de wayfinding, design gráfico-ambiental e señaletica que seguem.

\subsection{Wayfinding}

O termo "way-finding" foi usado primeiramente em 1960 pelo arquiteto Kevin Lynch o seu livro "A Imagem da Cidade" onde ele considerou os mapas, as ruas, a sua numeração, os sinais direcionais e outros elementos como auxiliares na busca ou como a "maneira de se encontrar". Seu trabalho é baseado no conceito da orientação espacial e seu pré-requisito é a capacidade que o ser humano tem para desenvolver o mapa cognitivo, o qual ele chama de imagem.

Lynch teve grande influência nas pesquisas realizadas nos anos 60 , porém não houve repercussão imediata no campo da sinalização e do design gráfico. No início dos anos 70 , os cognitivistas Steven Kaplan, Roger Downs e David Stea argumentaram que para se compreender o que as pessoas fazem para encontrar-se, devíamos entender o processo intrínseco. Este conceito foi importante pela introdução da noção de orientação espacial, e principalmente por incorporar todos os processos (perceptivos e cognitivos) necessários na tomada de decisão, no sentido de encontrar-se.

Wayfinding é um processo ativo, que requer o envolvimento mental e atenção ao meio ambiente por onde se está tentando navegar. O fato é, porém, que muitas pessoas são melhores em compreender a informação dada a eles verbalmente e por isso preferem 
perguntar a alguém como ir do ponto $A$ ao ponto $B$ do que seguir a sinalização ou ler um mapa. A sinalização e outras pistas visuais de wayfinding podem ajudar até mesmo essas pessoas a navegar pelo seu ambiente quando não há ninguém por perto para perguntar (CALORI, 2007).

O objetivo principal no wayfinding design pode ser chamado de wayshowing: permitir que cada pessoa forme um mapa mental de um espaço ou ambiente (CALORI, 2007). Portanto quanto mais claro for o layout físico do espaço, mais claros os mapas mentais serão. Em outras palavras, até mesmo o sistema de sinalização mais cuidadosamente pensado não pode resolver todos os problemas de circular em um lugar que contém caminhos confusos e tortuosos. São aspectos importantes do wayfinding design o planejamento espacial e a comunicação. Entende-se o planejamento espacial como a ordenação das informações na tomada de decisões. A orientação espacial pode ser considerada como uma relação estática com o espaço. No wayfinding design este relacionamento com o espaço é dinâmico (PASSINI, 1992).

Entende-se a comunicação neste contexto como catalisadora da percepção do espaço: a circulação, os fluxos (horizontal ou vertical), as referências, os marcos e o mais importante, a informação. Para Arthur e Passini (1992), a informação é concebida segundo critérios de legibilidade, visibilidade, compreensibilidade, estética, cor e forma. As informações podem ser classificadas em 3 grupos: 1) Informações para a tomada de decisões (definição de caminhos); 2) Informações para a execução das decisões (direção de caminhos); 3) Informações para a conclusão da tomada de decisões (identificação do destino).

Para os autores, o wayfinding design varia também conforme as condições em que o usuário se encontra, seja em situações de viagem; em locais de trabalho; em situações de lazer e entretenimento; em compras, em shoppings etc. As características dos espaços e ambientes também interferem no "encontrar-se": 1) O tipo de planta (simétrica, assimétrica, axial, circular); 2) Os fluxos (acessos, número de acessos, tipos de acesso: a pé, em veículos); 3) A circulação (horizontal, vertical); 4) As características arquitetônicas (fachada, estilo, cores, materiais).

\subsection{Design gráfico-ambiental}

Para Gail Deibler Finke, membra fundadora da SEGD - The Society for Experiential Graphic Design, autora de diversos livros e artigos publicados sobre esta matéria, os designers gráficoambientais têm a missão de tornar o espaço social mais "legível", sendo atribuição do designer responder ao contexto social e arquitetônico. O conceito de design gráfico-ambiental baseia-se concepção do projeto: faz parte do planejamento dos espaços e das construções desde o início do processo. O sistema de sinalização não é aplicado em ambientes acabados, é concebido como parte integrante daquele espaço.

O designer gráfico-ambiental deve ter o cuidado de moldar a informação ao seu contexto. Assim, o termo design gráfico-ambiental suplanta a ideia de sinalização (signage). Este sugere placas prontas, como os números prontos que são vendidos para identificar as casas. Esta distinção semântica, reforça e distingue a prática profissional e teórica.

Finke (1999) define duas características funcionais importantes: a facilidade de identificação e a facilidade de leitura. Entende-se por facilidade de identificação proporcionar à sinalização destaque do ambiente. Isto pode ser obtido através de algumas ações: aplicar a sinalização sempre de uma mesma maneira (mesma altura, do mesmo lado da estrada, etc.) ou seja, a sua consistência e coerência. Outra maneira é a sua forma, que deve ser evidentemente diferenciada das demais existentes no espaço.

Como facilidade de leitura, pode-se estabelecer que a localização da informação, o seu posicionamento, o seu dimensionamento adequado às distâncias de leitura necessárias, são fatores considerados. Independente destes aspectos funcionais, é de grande importância a característica destes projetos em dotar os espaços de uma "imagem": a história e a cultura devem ser observadas e podem ser expressas no ambiente.

Chris Calori (2007) apresenta o espectro desta atividade, que envolve a sistemática da informação coesa e um sistema gráfico visualmente unificado identificando o ambiente construído. Calori considera 3 funções importantes: 1) Sinalização e Wayfinding: que orientam os indivíduos e os ajudam a se deslocarem no ambiente; 2) Interpretação: que dá aos indivíduos informações acerca daquele ambiente; 3) Placemaking: provê aquele ambiente de uma imagem diferenciada.

A autora agrega a função interpretativa e o Placemaking aos já apresentados conceitos de sinalização e wayfinding. A primeira está associada à comunicação de um conceito ou tema, de um sentido cultural, social e/ou econômico adquirido intencionalmente no planejamento da 
comunicação visual. Isso pode ser atingido pela utilização de um objeto simbólico de um tema ou de uma figura histórica que personifique esse tema. Já a segunda se trata de um termo inicialmente utilizado por arquitetos e paisagistas americanos que significa "tratar espaços de forma diferenciada (praças, fontes etc)". Diferentemente de como é tratado pela arquitetura, placemeking no conceito de EGD tem a intenção explícita da comunicação.

\subsection{Señaletica}

O termo foi cunhado por Joan Costa em seu livro "Señalética" (1987). Esta obra faz parte de uma coleção editorial intitulada "Enciclopédia do Desenho", dirigida por Joan Costa, que engloba o estudo conceitual, metodológico e pragmático de diversas disciplinas do design a partir da ótica da comunicação.

"A Señalética nasce da ciência da comunicação social, ou da informação e da semiótica. Constitui uma disciplina técnica que colabora com a engenharia da organização, a arquitetura, o ambiente e a ergonomia, sob o vetor do design. A señalética responde à necessidade da informação ou orientação provocada e ampliada pelo fenômeno contemporâneo da mobilidade: deslocamento de grupos de indivíduos de diferentes procedências geográficas, condições sócio-econômicas e culturais distintas, implicando na ideia da circunstancialidade gerando novas situações" (COSTA, 1987).

Segundo o autor, entende-se por señalética o funcionamento instantâneo e automático da informação através de sinais visuais relacionados aos indivíduos. É uma disciplina técnica que se aplica à morfologia espacial, arquitetônica, urbana, e à organização dos serviços. Sua finalidade é a informação, inequívoca e instantânea. O seu funcionamento se dá através da interação das mensagens visuais e a reação a estas mensagens.

A señalética não impõe a atenção do público, não provoca impacto, nem recorre à atração estética. Talvez seja o exemplo mais significativo da comunicação funcional. Sua linguagem é predominantemente sintetizada, não discursiva e evita a retórica visual. Seu princípio é o da economia generalizada: máxima informação com o mínimo de elementos e com o mínimo de esforço do receptor para sua identificação e compreensão. Sua presença é silenciosa, sua ocupação é discreta, pode ou não ser utilizada, e deve desaparecer de imediato do campo de conhecimento do usuário.

As disciplinas e técnicas a ela relacionadas são: a programação visual, o planejamento, a arquitetura, a ergonomia, o entorno ou meio ambiente, e a produção industrial. Joan Costa considera que a señalética é uma evolução da prática da sinalização, aplicada a problemas particulares de informação espacial, que se integra ao espaço, ao ambiente e contribui para reforçar uma imagem de marca. Os sistemas de señalética se incorporam aos sistemas de identidade corporativa. Ainda para Costa a adaptação da señalética ao meio, é uma premissa fundamental desta disciplina e um dos principais fatores que a distinguem da sinalização.

Define a linguagem señalética, como sendo formada por: 1) Espaço gráfico: a limitação física do suporte material da informação; 2) O texto, ou figura; 3) A cor. Outra premissa da señalética é a organização do espaço tornando-o inteligível para o usuário. A señalética é totalmente centrada no indivíduo. A señalética deve ser adaptada ao meio em que se encontra. Um complexo desportivo, uma administração pública, uma estação de trem, cada um destes ambientes constitui universos particulares e as ações são determinadas a partir das funções a eles relacionadas. Por outro lado, a estrutura arquitetônica constitui outro aspecto do problema. As soluções adotadas para um ambiente arquitetônico simples ou complexo estão condicionadas a estas particularidades.

\section{Abordagem projetual: metodologia}

No presente estudo foram usadas como referência as metodologias focadas no desenvolvimento de projetos de wayfinding e EGD descritas nos trabalhos de David Gibson (2009) e Chris Calori (2015). Com nomenclaturas diferentes, os autores detalham os processos projetuais que seguem a mesma lógica descrita anteriormente, baseados nas subetapas aplicadas em escritórios de Design especializados nessa área do Design.

Gibson divide o que chama de "processo do Design" (figura 1) em três grandes etapas: Planejamento (pesquisa \& análise, estratégia, programação), Design (design esquemático, desenvolvimento do design, documentação da construção) e Implementação (suporte da oferta, administração da construção). Sua metodologia segue um objetivo claramente 


\section{CIDI 2017}

esportivo do Pacaembu $\mid 281$

operacional e técnico, que leva em consideração o empenho administrativo da implementação de projeto e as relações com fornecedores de material e serviços que entram no processo de implementação de projeto. Seu foco é comercial e se debruça sobre a viabilidade projetual, estabelecendo entregáveis claros para cada subetapa, desde o cronograma de projeto (que é, para o autor, o ponto inicial de qualquer projeto), passando por desenhos esquemáticos $\mathrm{e}$ orçamento de fabricação, até o fechamento do projeto com lista de pendências. Vê-se que, na verdade, o projeto é um processo cíclico cuja ação final é uma verificação dos pontos pendentes que aponta para um novo planejamento projetual.

Figura 1. O processo projetual de David Gibson

Planejamento
PESQUISA ESTRATÉGIA PROGRAMAÇÃO
\& ANÁLISE

$\begin{array}{ll}\text { Design } & \\ \text { DESIGN } & \text { DESENVOLV. DOCUMENTAÇÃO } \\ \text { ESQUEMÁTICO } & \text { DO DESIGN }\end{array}$

Implementação

SUPORTE DA OFERTA

Por outro lado, Calori foca nas ações estratégicas do designer e em seu papel na resolução de problemas (do cliente). Ela enumera seis passos evidentes no trabalho do designer: 1) Aferição do problema do cliente; 2) Aplicação das habilidades criativas; 3) Síntese da solução; 4) Comunicação da solução aos fornecedores; 5) Inspeção da implementação da solução; 6) Avaliação da efetividade do produto final.

O presente trabalho se propõe a estudar o problema a partir do levantamento de dados primários e secundários. Para tanto, foi feita uma pesquisa in loco em diferentes dias da semana e horários, garantindo uma captação de dados com a maior diversidade possível de perfis dos públicos que frequentam o Pacaembu. Ao todo foram seis dias de pesquisa que geraram 47 formulários de resposta, entrevistas em profundidade e 11 desenhos esquemáticos do clube com o intuito de verificar a composição do mapa mental criado pelos frequentadores do espaço. A análise do espaço e o desenvolvimento do projeto (itens 4 e 5 a seguir) foram respaldados, portanto, pelas metodologias identificadas na pesquisa bibliográfica e pelos dados coletados em visitas ao local - a percepção do próprio designer somada àquela dos usuários do Pacaembu.

\section{Análise do espaço}

O planejamento espacial atual do Pacaembu mudou pouco desde sua concepção. Além dos prédios, há espaços abertos como a quadra poliesportiva que é um destino a céu aberto dentro do clube, e a pista de corrida que é tanto uma via conectora quanto um destino em si. São três edifícios principais no espaço (figura 2). O primeiro abriga a piscina e seus vestiários, o ambulatório, o ginásio e seus banheiros e vestiários, e a lanchonete que funciona apenas em dias de eventos. $O$ segundo abriga as duas quadras de tênis com a antiga lanchonete e suas arquibancadas, a sala dos professores, banheiros e dois almoxarifados. O terceiro abriga o corredor da administração, uma sala de ginástica térrea, duas salas de ginástica inferiores, uma academia, banheiros, salas administrativas inferiores, copa, instalações de apoio para o estádio (sala de imprensa, três vestiários e acessos para o campo), salas de apoio policial, corredor de abrigo dos funcionários (com banheiros, armários, refeitório, vestiários e salas administrativas). Aqui não serão analisados os espaços que são de uso exclusivo dos eventos futebolísticos do estádio, que está de fora do escopo do projeto. 


\section{CIDI 2017

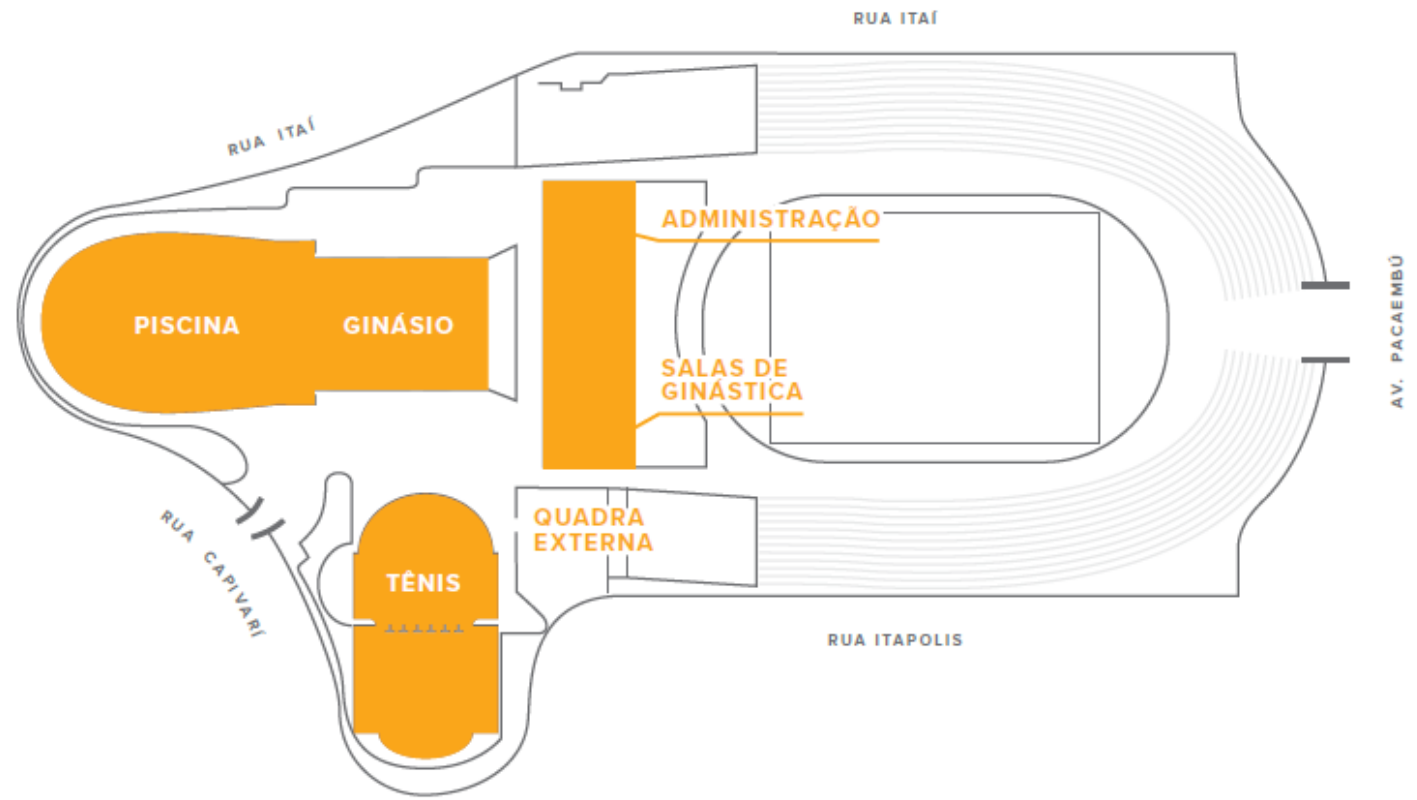

A planta do Pacaembu, apesar de ser assimétrica, é pouco complexa. Há uma via principal (figura 3) que faz uma circulação elíptica ao redor do complexo todo e também serve de pista de corrida. Há uma via menor que tem grande fluxo, passando na parte posterior do ginásio, a qual é utilizada para acessar as salas de ginástica e o corredor da administração. $\mathrm{Na}$ via principal, carros e pedestres dividem espaço no trecho entre a frente do ginásio e o corredor administrativo, passando pelo portão da Rua Capivarí, pois estas duas pontas são as áreas onde há estacionamento para os carros. Nestas vias o fluxo tem picos claros, principalmente no período da manhã, nos horários de início e fim das aulas oferecidas no clube (figura 4).

Figura 3. Estacionamento principal.

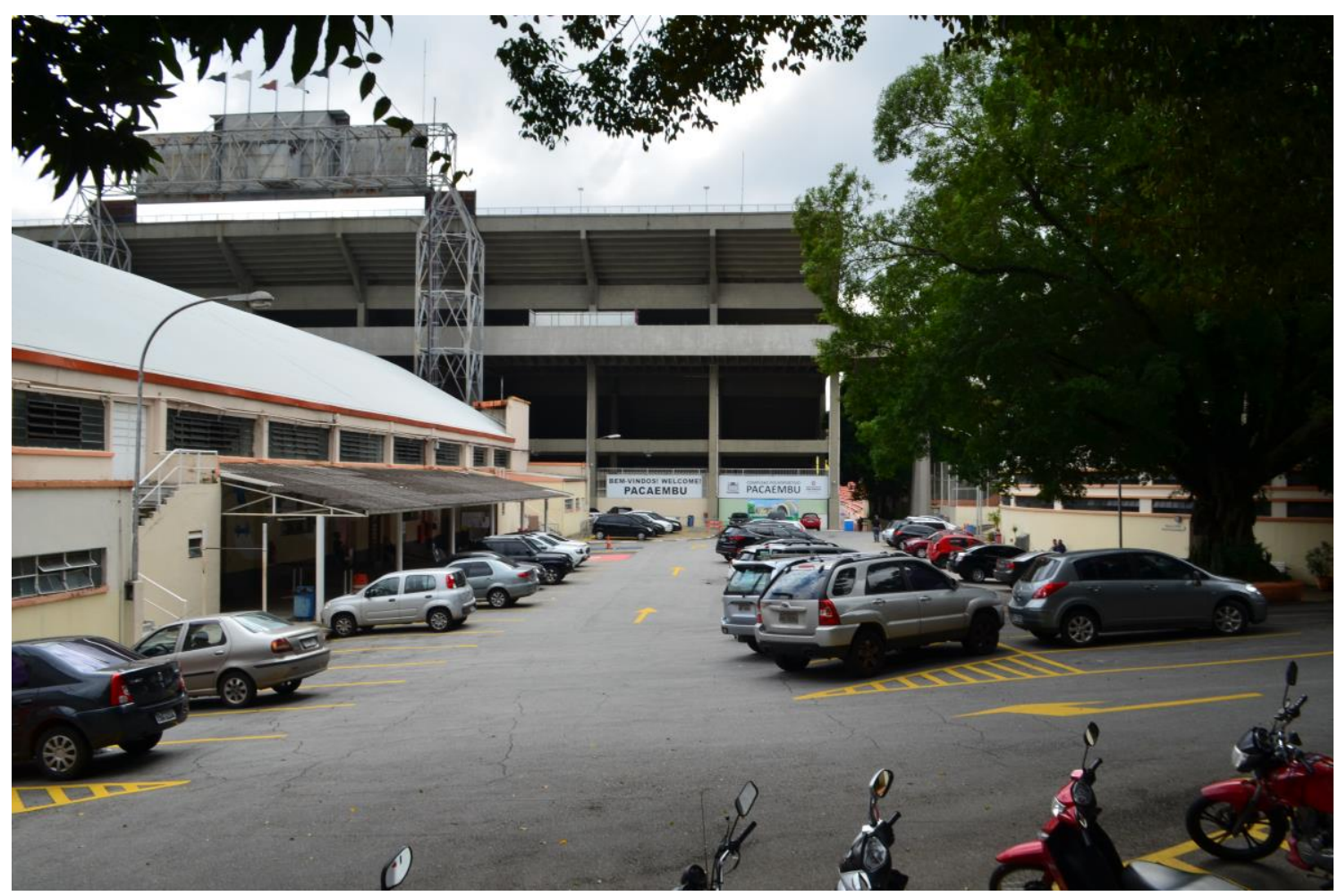




\section{CIDI 2017

Figura 4. Principais rotas e destinos do complexo.

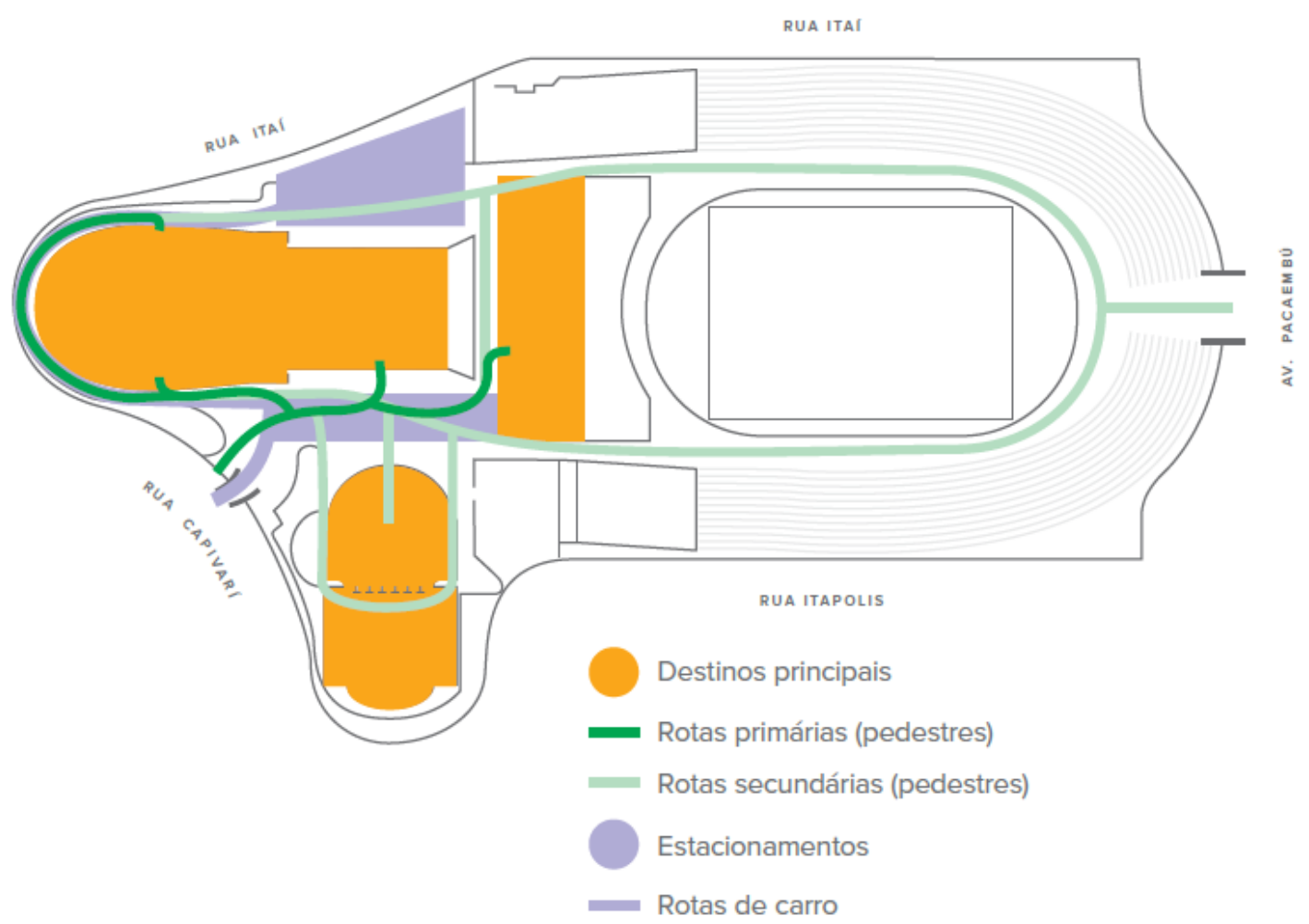

Entre os prédios do complexo não se vê diferença arquitetônica, seja estilística, cromática ou material. Eles são os marcos do clube, confundindo-se com os setores que estão alojados dentro deles. A compreensão do espaço tira proveito do histórico das edificações e de seu descompasso com a evolução arquitetônica do entorno. No entanto, fora a manutenção dos edifícios originais do complexo, nenhum esforço é empregado na comunicação e na construção do mapa cognitivo de seus públicos para que sua imagem seja reforçada. A semântica do espaço é de difícil decodificação, oferecendo pouco - ou nenhum - suporte para a construção de uma imagem bem estruturada.

Considerando os três tipos de informação que o espaço pode e deve comunicar a seus usuários (definição de caminhos, direção de caminhos e identificação do destino), o tipo que é mais bem-resolvido no projeto atual é o de informações para definição de caminhos. A pouca quantidade de vias e prédios, dentro de uma área de fácil memorização pelo tamanho diminuto, facilita o entendimento do que são caminhos e para onde eles levam. Mesmo assim, algumas ressalvas devem ser feitas. São dois acessos para as quadras de tênis, sendo que um deles é o principal e outro passa por um corredor onde está a porta da sala dos professores. Nenhum dos dois é claramente identificado e, para quem já está dentro do complexo, a própria parede da fachada do setor tênis cobre a visão do acesso. Além disso, o acesso às salas de ginástica também não é claro para o visitante desavisado e desconhecedor do complexo (figura 5). Por último, na parte de trás do edifício das salas de ginástica há uma disposição confusa de cômodos, somada à péssima iluminação, portões fechados que bloqueiam o caminho e escadas que cortam as vias, tudo contribuindo para uma total indefinição de caminhos. 


\section{CIDI 2017

Figura 5. Acesso para o corredor das salas de ginástica e vestiários.

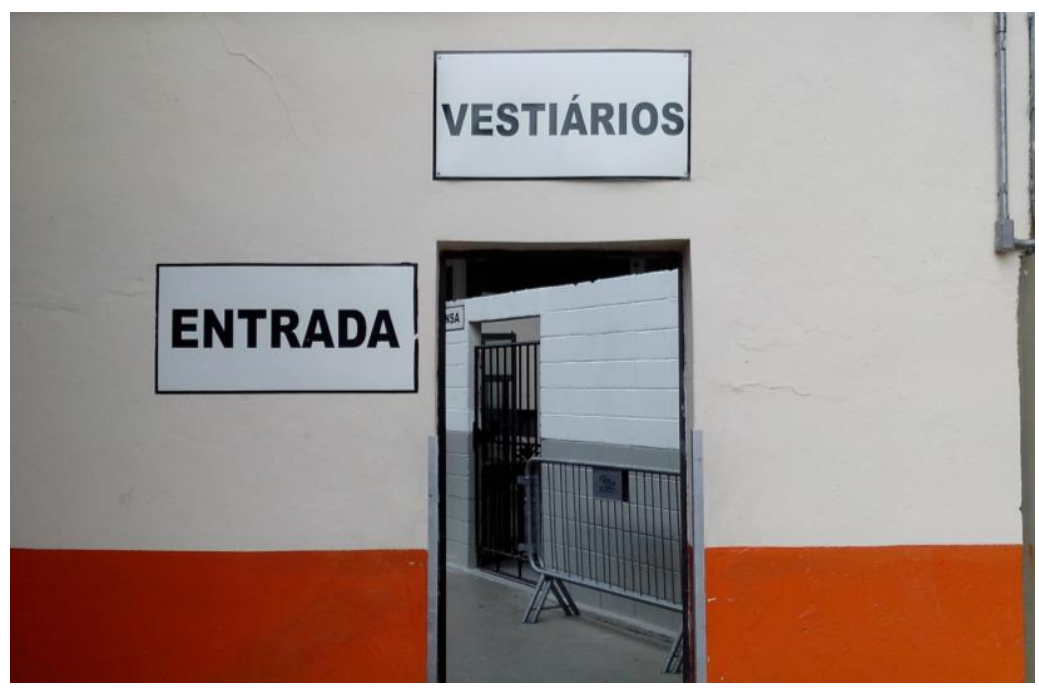

As informações para a tomada das decisões, em sua maioria, estão mal posicionadas ou ausentes. A altura e tamanho dos textos não segue nenhuma recomendação de design, não seguindo também um padrão de posicionamento em relação aos caminhos que indicam. É possível encontrar, por exemplo na área de trás do edifício das salas de ginástica, indicações contraditórias de saída e não há indicação para banheiros e vestiários em lugar algum que não seja na porta dos mesmos.

As placas colocadas na área do clube são, principalmente, de caráter de identificação e regulatório. Praticamente não se vê os outros tipos de conteúdo informacional - direcional, de advertência, operacional, honorífico e interpretativo - e quando se vê é indicando o caminho da saída. O sistema como um todo pressupõe que o visitante já saiba como funciona a rotina do clube, deixando de indicar os subdiretórios como as salas de ginástica e academia, os banheiros menores e até mesmo a existência de mais de uma quadra de tênis.

Observando as placas e sinalizações pintadas, claramente implementadas em momentos diferentes da história do clube, não há nenhuma coesão na metodologia de implementação das peças. Não há estudo para a altura das peças nem para sua localização dentro dos setores. Muitas vezes não há sinalização onde deveria, seja de caráter regulatório, informacional ou direcional, e muitas vezes há uma redundância de placas, como é visto em frente à sala de ginástica inferior com as placas de "proibido fumar". Essa falta de coesão não se dá apenas à arquitetura da informação, mas também à linguagem gráfica das peças (figuras 6 e 7).

Figura 6. Placas de banheiro sem coesão estilística.

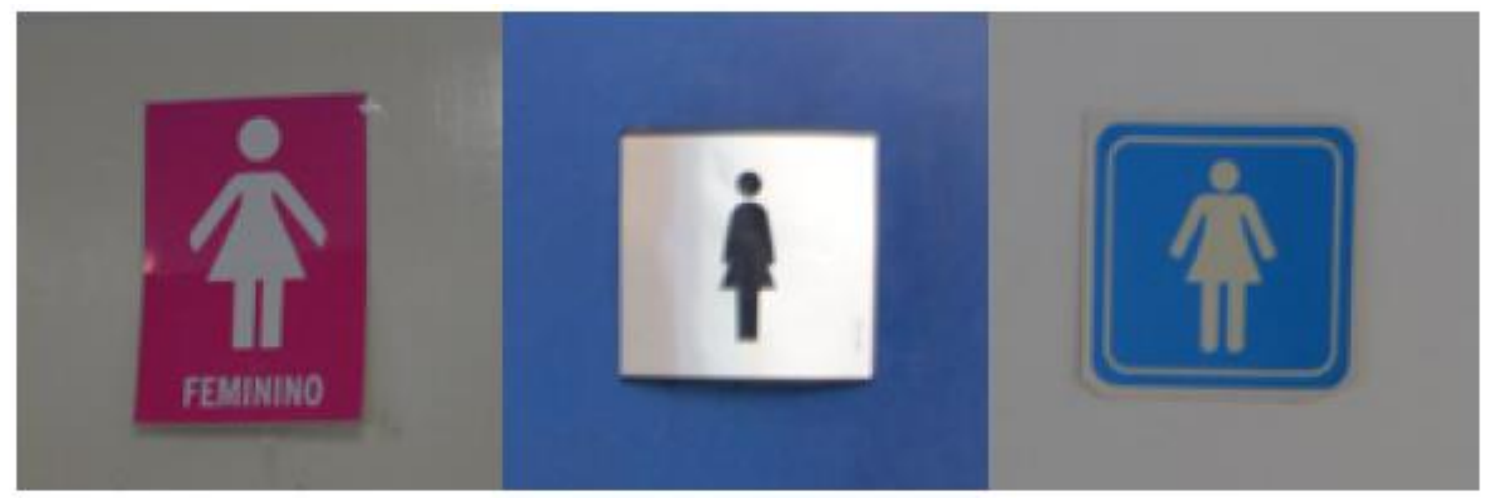




\section{CIDI 2017

Figura 7. Placas de vestiário.

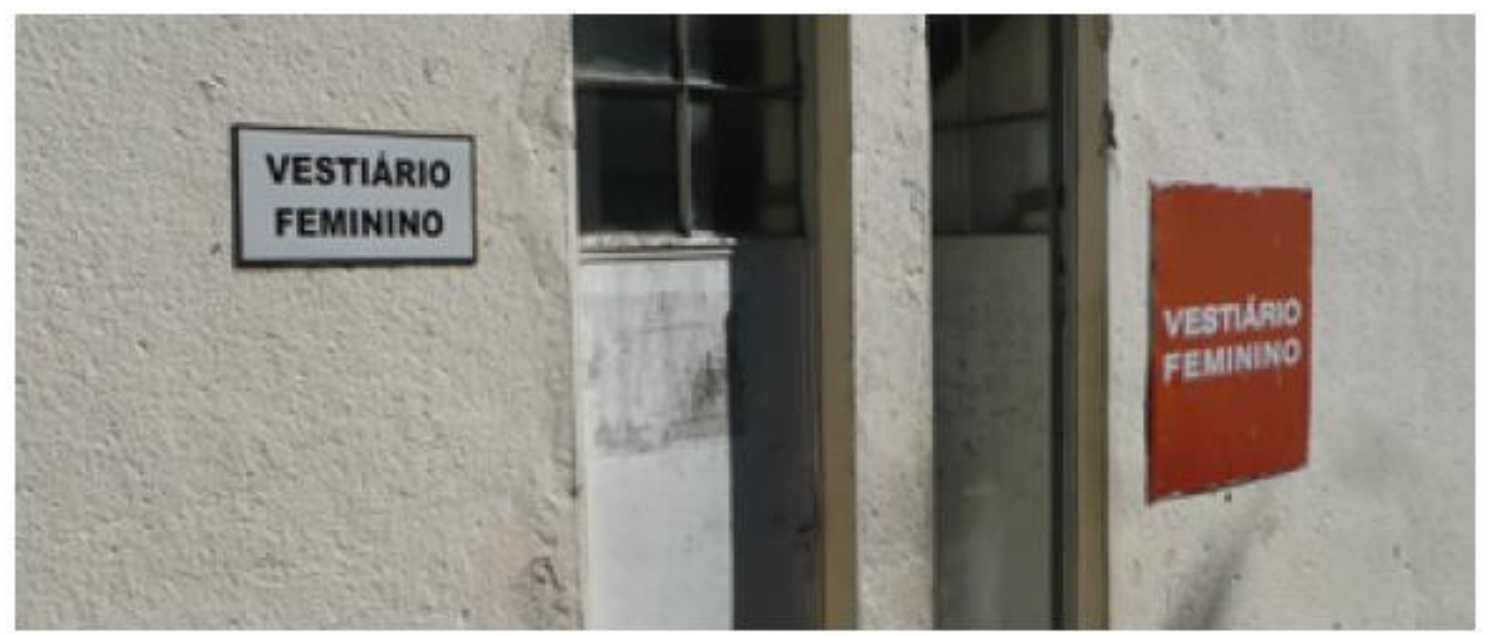

A falta de hierarquia e sistematização não se restringe ao tamanho e linguagem das placas, mas também ao tamanho e ênfase dada às informações. Não há nenhuma tipologia planejada perceptível que separe os tipos de informação, seja por tamanho, cor, material, acabamento ou peso visual. Essa falta de planejamento é comprovada pela grande quantidade de avisos e informes pendurados de maneira improvisada em quase todas as áreas de descanso - que não são vias de acesso ou conectores - do complexo (figura 8).

Figura 8. Informes presos de forma improvisada.

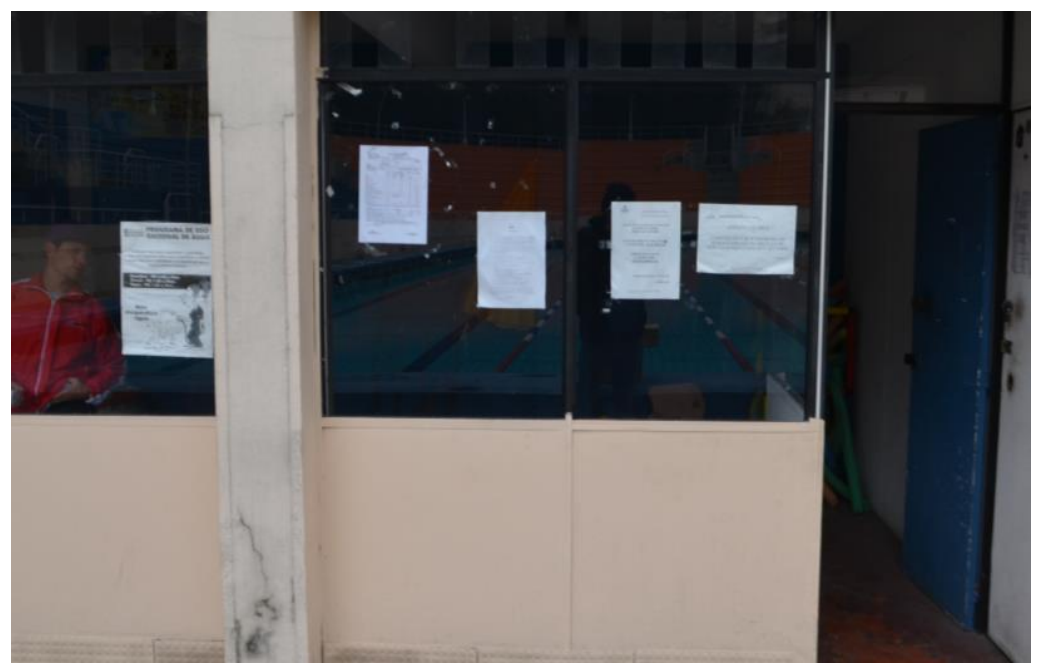

Quanto ao sistema de suportes, o tamanho das placas e sinais gráficos não levam em conta a distância da qual as pessoas buscam as informações sinalizadas, não tendo critério para a escolha das dimensões e direções dos suportes. Há, basicamente, três tipos de suporte utilizados no clube: pinturas na parede, placas retangulares de papel grosso e placas prontas de mercado (principalmente de proibido fumar e de saída). É comum ver sinalizações de entrada (as únicas referentes a orientação e direção) no mesmo estilo e tamanho das sinalizações de identificação.

\section{Desenvolvimento do projeto}

A resolução dos problemas de percepção total do espaço, conscientização do movimento e singularidade dos espaços, bem como uma melhor percepção das possibilidades de seu uso e melhora da locomoção nas áreas de circulação de carros e pedestres foram o foco do desenvolvimento projetual. Isso é estimulado, nesta proposta para o clube, pela implementação de pequenos canteiros verdes com postes de luz baixos, que tornam o espaço mais agradável 


\section{CIDI 2017

esportivo do Pacaembu| 286

ao mesmo tempo em que reduzem sensivelmente o espaço para circulação de carros. $O$ nivelamento do piso também faz com que rampas de acesso para cadeirantes sejam abolidas, permitindo 0 acesso a pedestres e cadeirantes indiscriminadamente (figura 9).

Figura 9. Nova fachada do ginásio e estacionamento principal.

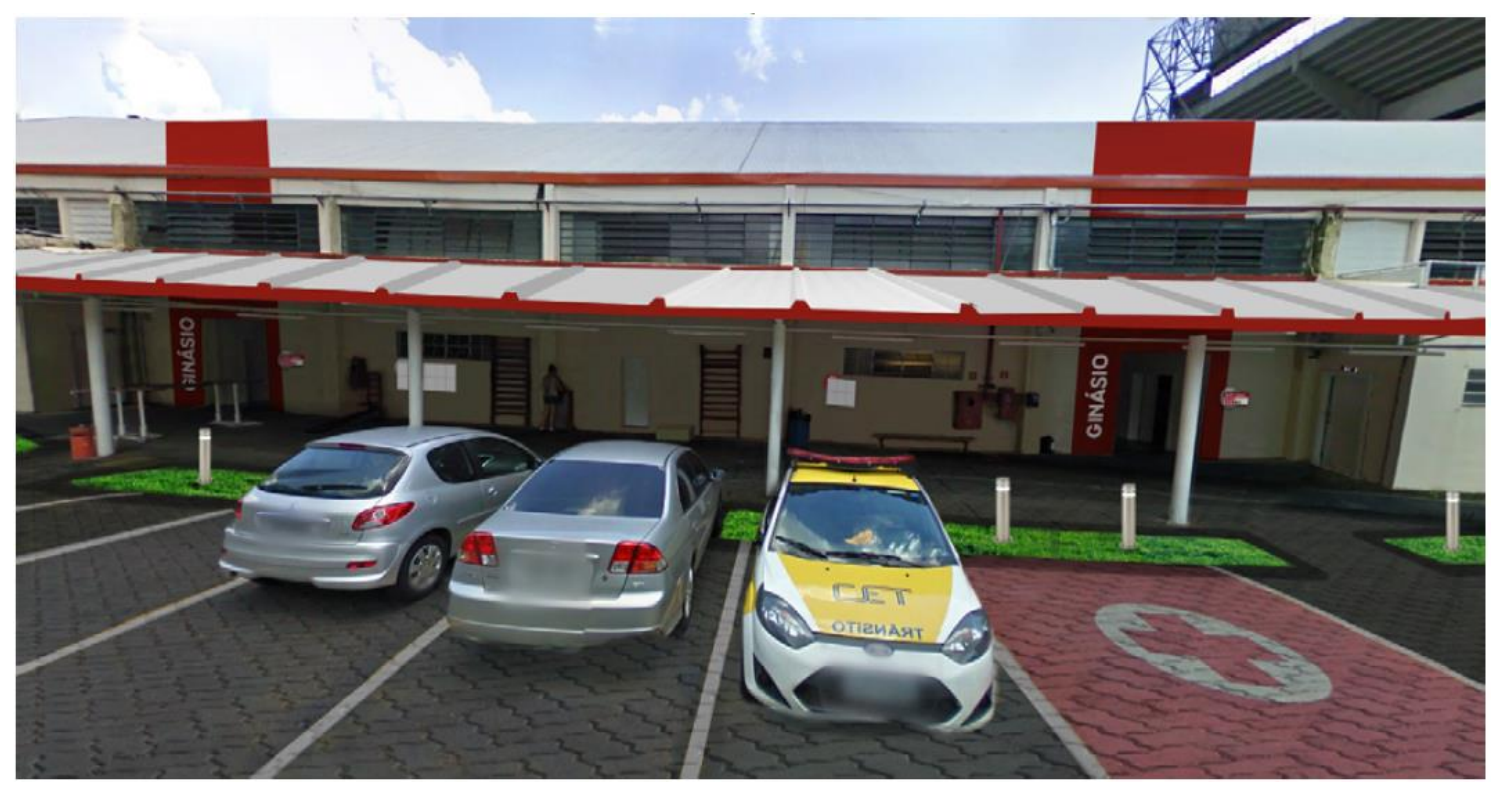

Por outro lado, toda a identidade visual gráfica, sua comunicação e eficiência foram melhorados com a sistematização em cores dos diferentes setores. Isso garante que os espaços do clube não só tenham uma clara e fácil identificação de suas funções (novamente uma melhoria em suas singularidades), mas facilita o mapeamento mental, bem como a identificação dos espaços a distância, principalmente por pessoas de visão comprometida (seja por idade avançada ou deficiência). Na documentação do projeto, os desenhos técnicos e imagens ilustrativas foram desenvolvidas para representar a nova proposta de sistema de comunicação visual ambiental (figuras 10 a 16).

Figura 10. Corredor lateral que liga os estacionamentos.

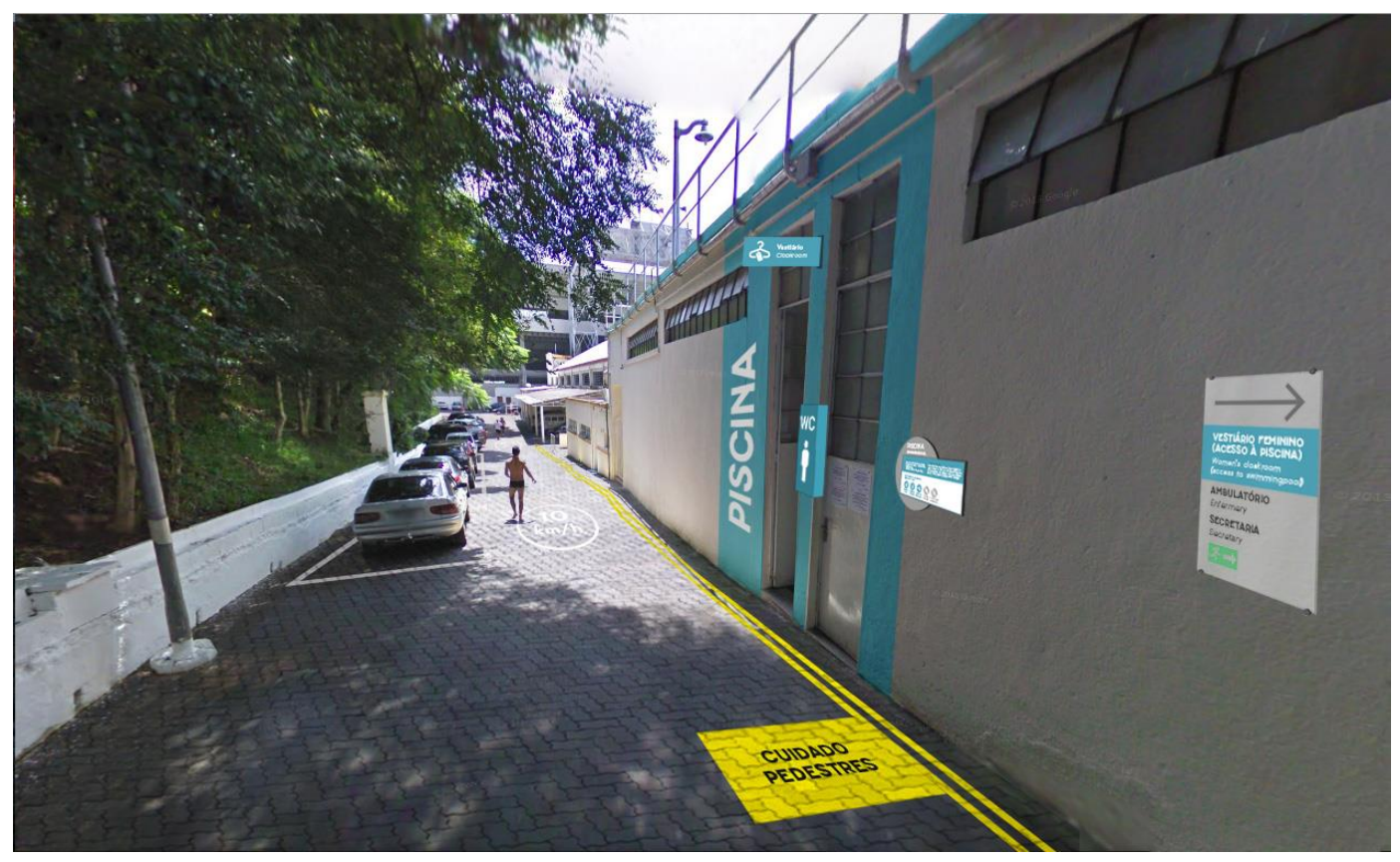




\section{CIDI 2017

Figura 11. Proporções das peças de comunicação e as cores de cada setor.
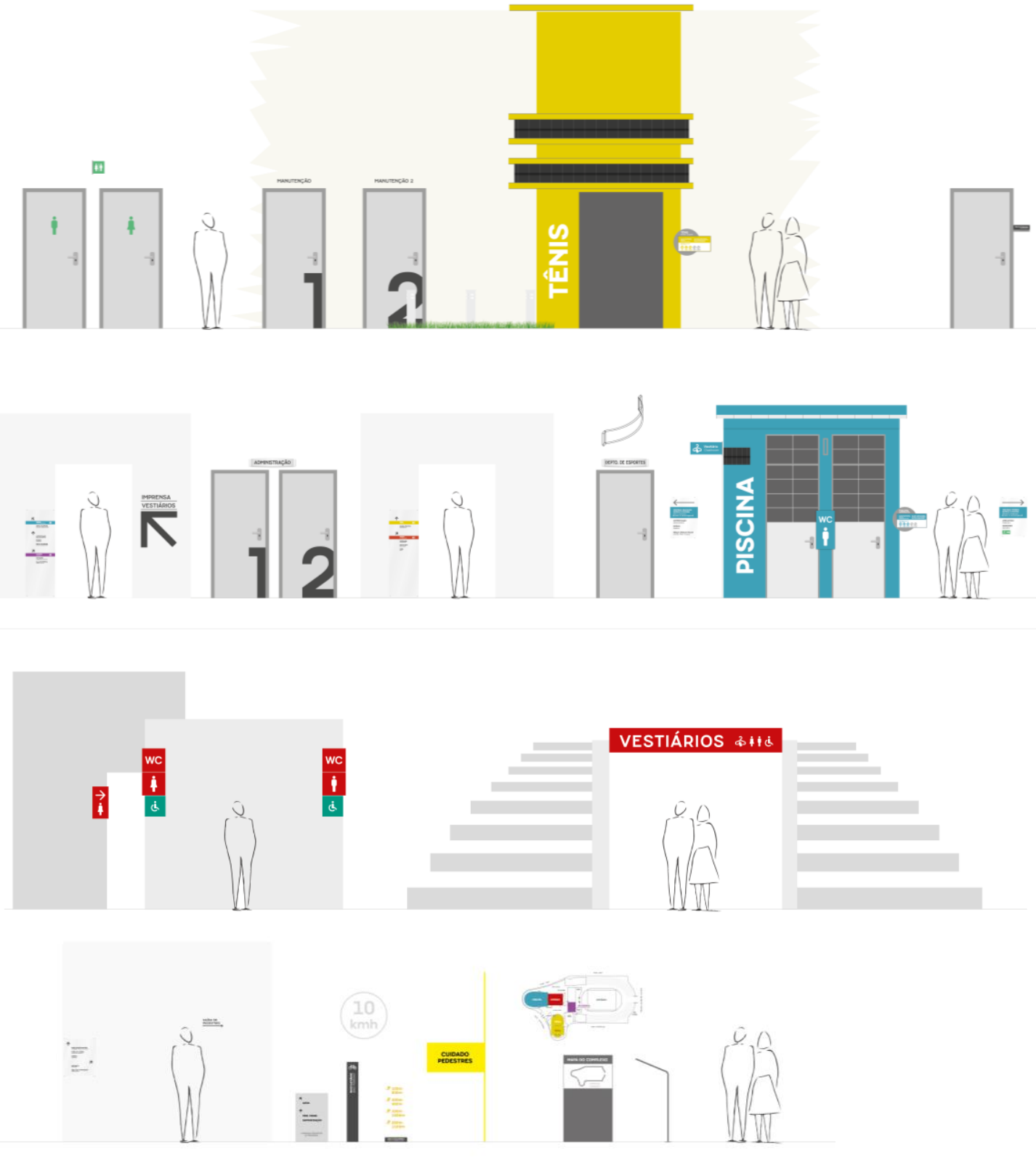

Figura 12. Placas de identificação de portas.

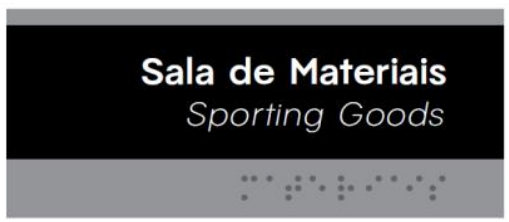

210

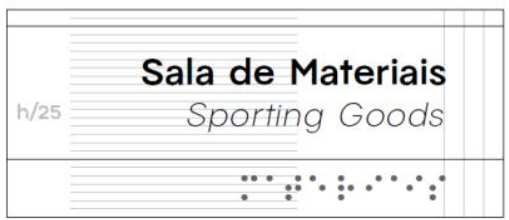

\section{DEP. DE ESPORTES}

SPORTS DEPARTMENT

\section{DEP. DE ESPORTES}

SPORTS DEPARTMENT 


\section{CIDI $2017 \quad 8^{\text {th }} \mathrm{CIDI}$

Figura 13. Placa informativa do acesso da piscina.

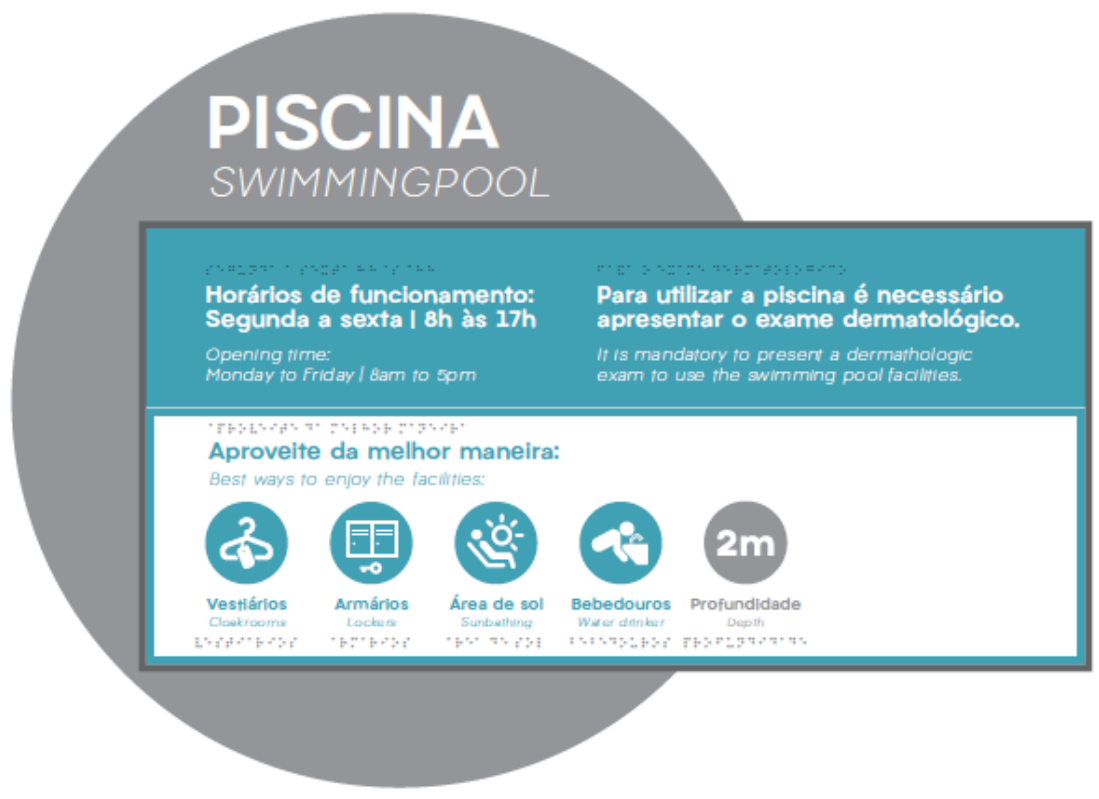

Figura 14. Iconografia utilizada no projeto.
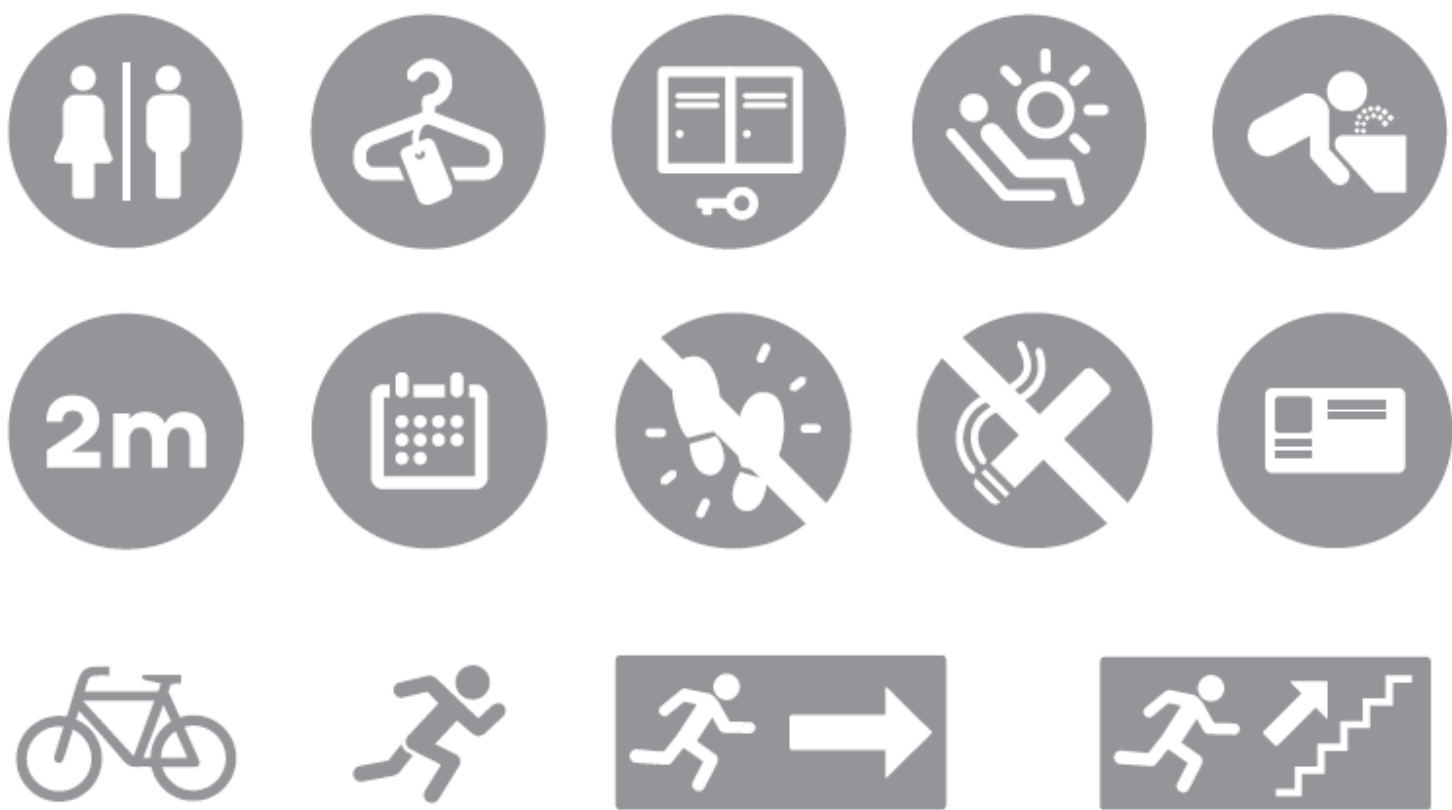


\section{CIDI 2017

Figura 15. Tipo desenhado exclusivamente para o projeto pelo tipógrafo Álvaro Franca.

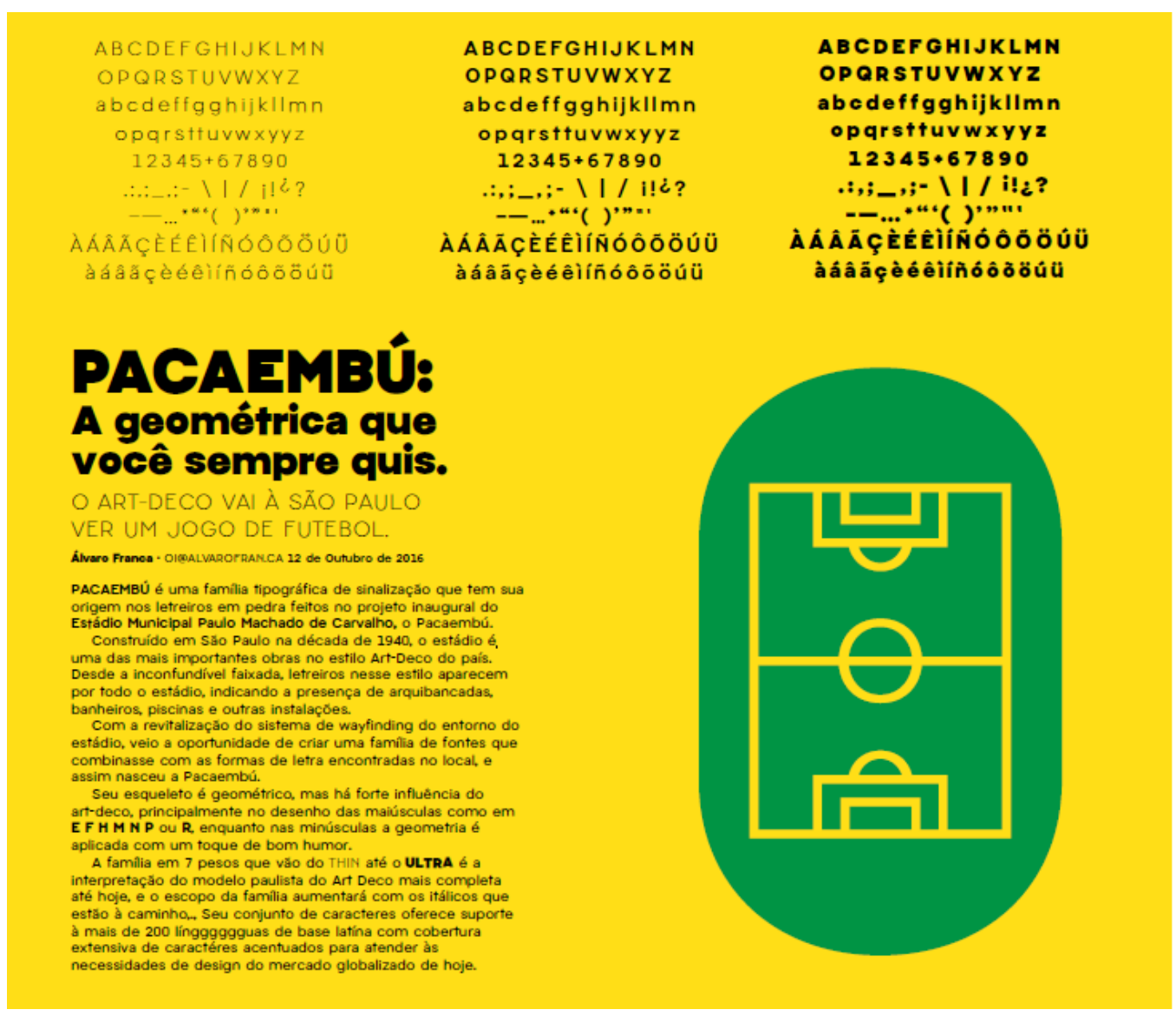

Figura 16. Totens orientacionais de parede.
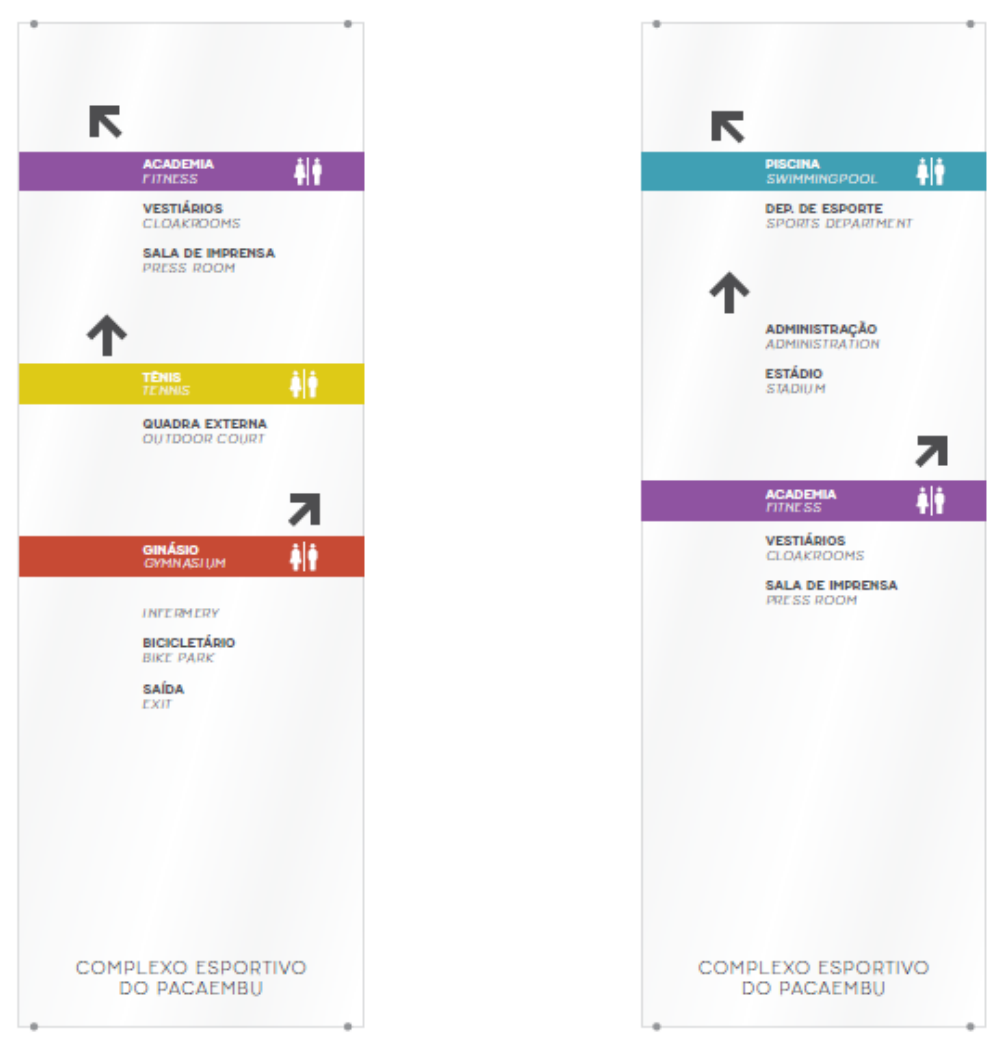
Esta facilidade de acesso à informação sobre os setores também é trabalhada nas placas que tem funções operacionais de advertência, como as placas posicionadas ao lado dos acessos principais de cada setor. A padronização dos diferentes tipos de informação também contribui para que a informação seja mais facilmente apreendida, e assim vê-se que há critérios para a forma como as peças de comunicação ambiental são desenhadas e posicionadas. Há três principais tipos de identificação de portas e acessos: as plaquetas de parede pequenas, que ficam ao lado das portas de ambientes internos onde a leitura é feita de uma distância menor, posicionadas à altura de ombro; as plaquetas de parede grandes, que ficam acima ou ao lado das portas (dependendo do espaço que existe em volta do batente) de ambientes externos onde a leitura é feita de uma distância maior; e as pinturas de fachada que identificam os principais acessos dos setores, que tem destaque tanto pela importância dos setores no uso do clube, quanto por serem os principais destinos dos transeuntes.

\section{Conclusão}

Espera-se que o desenvolvimento de um projeto de comunicação visual-ambiental para o Complexo Esportivo do Pacaembu, um marco histórico e cultural da cidade, possa suscitar possibilidades para o tratamento de outros espaços públicos de lazer da cidade de São Paulo. Projetos elaborados para celebrar os significados históricos e culturais da cidade contribuem para a crescente discussão sobre o apoderamento do espaço público que tem entrado na pauta do paulistano. $O$ ato de projetar para um espaço de dimensões culturais e sociais desse porte é um grande desafio para os designers.

Verificando a evolução e os resultados deste projeto, considera-se que o protagonista do resgate da herança cultural que o Pacaembu deixa pode não ser necessariamente a arquitetura em si. Não seria a retomada do art-nouveau e o saudosismo do que o Pacaembu já foi. Mas sim o uso do espaço em todo seu potencial, adequado à vida contemporânea, trazendo as pessoas para dentro inadvertidamente como se não houvesse muros tombados escondendo os espaços de convívio e lazer que unem as pessoas. Esta hipótese foi construída com a aplicação pesquisa exploratória baseada em entrevistas com usuários do clube, que também geraram desenhos de memória da planta do Pacaembu, e responderam ao questionário que visava identificar os perfis de público dos sócios, associadas à muitas visitas de observação.

A experiência revelou uma prática de design centrada em um resultado transformador do espaço para as pessoas e não das pessoas para o espaço. Ou seja, em oposição ao uso dos elementos visuais ambientais como uma mera extensão do plano de comunicação, que muitas vezes é apenas adaptado para essa finalidade. Deixa-se de perceber as diferenças essenciais que existem entre eles e os suportes midiáticos tradicionais, com a possibilidade de conquistar o espaço invés de ser conquistado por ele.

\section{Referências}

ARTHUR, P.; PASSINI, R. 1992. Wayfinding People, Signs, and Architecture. New York: McGraw-Hill.

CALORI, C. 2015 Signage and wayfinding design: a complete guide to creating environmental graphic design systems. New Jersey: John Wiley \& Sons.

COSTA, J. 1987. Señalética. Barcelona: Ediciones Zeus.

FINKE, G. D. 1999. You are here: Graphics that direct, explain \& entertain. St Books.

GIBSON, D. 2009. The wayfinding handbook: Information design for public places. New York: Princeton Architectural Press.

LYNCH, K. 1997. A imagem da cidade. Tradução Jefferson Luiz Camargo. São Paulo: Martins Fontes.

PAUWELS, L. (2009). Street Discourse: A Visual Essay on Urban Signification. Culture Unbound, Linköping, v. 1, p. 263-272. 2009

VELHO, A. L. O. L. O Design de Sinalização no Brasil: a introdução de novos conceitos de 


\section{CIDI 2017 selch

1970 a 2000. 2007. 184 f. Dissertação (Mestrado em Design). PUC-Rio.

SPTuris. São Paulo é considerada cidade mais influente da América Latina, 2015. <

http://imprensa.spturis.com.br/press-kits/sao-paulo-e-considerada--cidade-mais-influente-daamerica-latina >, 08/10/2016

\section{Sobre o(a/s) autor(a/es)}

Fabio Salmoni; graduado, ESPM e FAU-USP, Brazil < salmoni@umcomum.com.br > Sara Goldchmit, PhD, FAU-USP, Brazil < saragold@usp.br > 